\title{
How to Use This Book
}

Preliminaries. Some units begin with a section called Preliminaries. This is designed to provide the student with an introduction to or review of some basic terminology and concepts of grammar. It is impractical to study ancient Greek, a language rich in inflectional forms and permitting a highly variable word order, without an understanding of these concepts. References to other languages here or in the units themselves are given both for the purpose of comparison to benefit students who may have studied other languages and in order to demonstrate that English inflection is anomalous in its simplicity, that grammatical structures in English are not the only possible ones, and that the richness and complexity of Greek are paralleled in many other languages. These comparisons can be passed over by those who do not find them useful.

Vocabulary. The vocabulary is intended to familiarize the student with a fairly large sample of basic and frequently occurring words, memorization of which will facilitate reading of all kinds of Greek as the student progresses. Unit vocabularies are laid out in columns, allowing the student to cover one column or the other with a piece of paper for study and drill. The online supplements at atticgreek.org contain a flexible vocabulary drill, and one can search the Internet for other digital flashcards. A set of a thousand vocabulary cards with classical Greek words commonly used in the authors most read in college courses is published by Visual Education Association and is available from booksellers. 
Principal Parts. Whenever verbs are introduced in a unit vocabulary, there is also a list of all the principal parts. This format gives the instructor complete freedom to advise the student how many principal parts to try to memorize at what particular point in the course: in some courses one may want all six principal parts learned at once; in others one may take a more gradual approach, such as learning the first principal part in Units 5-17, learning the first three from Unit 18 through Unit 28, and adding the aorist passive in Unit 29 and the remaining two in Unit 37. In Appendix B all the principal parts are presented alphabetically and in columns, so that particular columns can be shown or concealed. The online supplements at atticgreek.org contain a flexible principal parts drill.

Exercises. The exercises of a unit are keyed to the grammar and vocabulary for which the student has been prepared to that particular point. Especially in the first part of the book I have tended to avoid introducing new words or constructions in a reading exercise, so that a student who has truly mastered the material to date should be well equipped to do the reading with a minimum of annotation or reference to the glossary. Occasionally a unknown word is used but glossed. The reading exercises emphasize commonplace prose usage, so that students will be able to develop sensitivity to poetic and recondite language when they later encounter it.

Glossaries. The Greek-English Glossary is a compilation of all the vocabulary assigned in the book. For each word the unit number is added, so that the instructor and student can easily determine what words the class is responsible for any given point in the course, and one can refer back to the unit for further definitions and information about usage. The English-Greek Glossary is limited to providing the Greek equivalents for the English words that appear in the exercises (whether single words, phrases, or sentences). There too the unit number is provided to allow reference to more extensive treatment.

Memorization and Drill. It cannot be too strongly emphasized that reading real Greek will be more enjoyable and easier if one masters enough important vocabulary and the most common inflectional patterns in the elementary course. People differ in the ease with which they memorize and in the manner in which they do so most effectively. Some people have excellent visual memory and need only to look at paradigms and vocabulary repeatedly and carefully; others do better by repeatedly pronouncing and hearing the items to be memorized; others may find that writing out inflections and words helps memorization. (For many, it is more effective to write out their own flashcards rather than purchase a printed set.) It is usually best to use several techniques, and it is always to be recommended that students pronounce words aloud while studying and recite important inflectional patterns. The student 
must learn to drill himself or herself (or to collaborate with a fellow student), because in a college course there will never be time for enough drilling in the classroom.

The exercises help to determine how well one has mastered the vocabulary, inflections, and grammatical rules learned so far. Doing the exercises, however, is no substitute for the task of basic memorization that is necessary in the beginning stages of any language. There are several ways to complement the exercises given in the units if one wants more practice:

1. Repeat the exercises after an interval. (Avoid writing the answers in the book.)

2. Use the example phrases and sentences within the units for practice and review by covering up the translations.

3. Write out paradigms.

4. Do an exercise in reverse, working back from the corrected answers.

5. Vary the given exercises by altering the instructions according to a fixed pattern. (E.g., interchange singular and plural, active and middle/passive; transpose the case of a noun or the tense of a verb.)

6. Apply a sequence of instructions to the words listed in the vocabulary. (E.g., proceed through a list of nouns giving genitive plural of the first, accusative singular of the second, dative plural of the third, etc.)

Taking Advantage of Patterns. With such a rich vocabulary, so many principal parts, and so much inflection, ancient Greek can seem a daunting challenge. Not everything will stick the first time one tries to master it, and by the time one gets to the late units, the total number of details may seem overwhelming. That is why it is so important to pay attention to patterns and to learn to recognize a form not because one has memorized that particular form but because one recognizes the elements from which is it composed. (For example, for a verb form, the prefixed elements, the tense stem, and the ending.) For every new paradigm presented, the student should try to emphasize to herself or himself what is generalizable and what is akin to items already learned.

Online Supplements. Online tutorials keyed to this book provide additional materials of various kinds and may be found at atticgreek.org. These include alternative versions of the presentation of pronunciation (with recorded examples) and of accentuation (with more visual aids). There are also flexible drills for vocabulary, principal parts, and inflectional forms, as well as a version of Appendix C (Paradigms). In addition, several lists of principal parts in alternative arrangements are available for download, as well as blank paradigm charts and a verb synopsis grid, and short documents on other topics, such as word order or transitioning to reading continuous passages of Greek. 


\section{ABBREVIATIONS AND OTHER CONVENTIONS}

\begin{tabular}{|c|c|c|c|}
\hline$A$ & antepenult & impf. & imperfect \\
\hline a. & accusative & impt. & imperative \\
\hline acc. & accusative & ind. & indicative \\
\hline act. & active & indef. & indefinite \\
\hline adj. & adjective, adjectival & inf. & infinitive \\
\hline adv. & adverb, adverbial & interrog. & interrogative \\
\hline aor. & aorist & intrans. & intransitive \\
\hline art. & article & irreg. & irregular \\
\hline cf. & confer, compare & $\mathrm{m}$ & masculine \\
\hline comp. & comparison, & $\mathrm{m} . / \mathrm{p}$ & middle/passive \\
\hline & comparative & masc. & masculine \\
\hline complem. & complementary & mid. & middle \\
\hline conj. & conjunction & n. & neuter \\
\hline d. & dative & n. & nominative \\
\hline d. & dual & neut. & neuter \\
\hline dat. & dative & nom. & nominative \\
\hline demonstr. & demonstrative & obj. & object \\
\hline e.g. & $\begin{array}{l}\text { exempli gratia, } \\
\text { for example }\end{array}$ & $\begin{array}{l}\text { obl. } \\
\text { opt. }\end{array}$ & $\begin{array}{l}\text { oblique } \\
\text { optative }\end{array}$ \\
\hline Ex. & Example & $P$ & penult \\
\hline f. & feminine & p. & plural \\
\hline fem. & feminine & part. & participle, \\
\hline fut. & future & & participial \\
\hline g. & genitive & pass. & passive \\
\hline gen. & genitive & perf. & perfect \\
\hline gen. & genuine & pers. & person, personal \\
\hline i.e. & id est, that is & pl. & plural \\
\hline imper. & imperative & plup. & pluperfect \\
\hline imperat. & imperative & pluperf. & pluperfect \\
\hline imperf. & imperfect & plur. & plural \\
\hline impers. & impersonal & Prelim. & Preliminaries \\
\hline
\end{tabular}




$\begin{array}{llll}\text { prep. } & \text { preposition, } & \text { superl. } & \text { superlative } \\ & \text { prepositional } & \text { suppl. } & \text { supplementary } \\ \text { pres. } & \text { present } & \text { trans. } & \text { transitive } \\ \text { princ. } & \text { principal } & U & \text { ultima } \\ \text { pron. } & \text { pronoun, pronominal } & \mathrm{U} & \text { Unit } \\ \text { rel. } & \text { relative } & \text { v. } & \text { vocative } \\ \text { s. } & \text { singular } & \text { voc. } & \text { vocative } \\ \text { sing. } & \text { singular } & 1 \text { st } & \text { first, first person } \\ \text { sp. } & \text { spurious } & \text { 2nd } & \text { second, second person } \\ \text { subj. } & \text { subject } & 3 \text { rd } & \text { third person } \\ \text { subj. } & \text { subjunctive } & & \end{array}$

(above a vowel) indicates that the vowel is long, or (in a metrical scheme) indicates a metrically heavy (long) syllable (above a vowel) indicates that the vowel is short, or (in a metrical scheme) indicates a metrically light (short) syllable before a Greek form indicates that it is reconstructed (early), not actually documented between two Greek forms indicates that the first developed into the second in a process of linguistic change with (in reference to grammatical construction) 
This page intentionally left blank 